\title{
COMMENTARY
}

\section{Conventional medicine is less than perfect}

Despite the poor evidence base behind many complementary therapies and the lack of proper licensing and governance in many areas, complementary medicine is popular with many. This issue of the BJGP features a discussion of some of the ethical deficits that are allowed to continue in day-to-day practice in the burgeoning complementary medicine field. ${ }^{1}$

Of course, it is trying for conventional medical practitioners to witness the apparently free hand afforded complementary therapists while their own practice is increasingly affected by demands that it must be guided by evidence of clinical- and cost-effectiveness, for continuing assessment of professional standards, and for respect for ethical and data protection constraints. In such circumstances, challenges to ethical standards in complementary medicine are both understandable and inevitable.

But conventional medicine should exercise caution and honesty in its challenges to complementary medicine. While commentators from conventional medicine may rightly feel that they are on firmer ethical ground, it would be wrong to imply that conventional medicine is ethically flawless. One does not have to look to the newsworthy or the dramatic. There are many more workaday instances in which conventional medicine's ethical standards can be challenged.

For example, informed consent is indeed a prerequisite for both medical research and clinical practice. And it may be true that many practitioners of complementary medicine fail to obtain informed consent before treating a patient. But is genuinely informed consent universally sought in the practice of conventional medicine? For example, the prostate specific antigen (PSA) test is widely used as an indicator of presymptomatic prostatic cancer. However, it yields considerable numbers of false positives, leading to unnecessary anxiety and often a potentially risky biopsy, and there remains considerable debate as to whether early detection is beneficial. ${ }^{2}$ Given pressures of time and other factors, it seems unlikely that all patients give genuinely informed consent: the decision is emotionally charged and to give genuinely informed consent patients would require a considerable amount of time and preferably some knowledge of epidemiological principles to discuss it with their doctor. Likewise, conflicts of interest can affect conventional medicine just as they can complementary medicine: while in private practice payment-led incentives to perform tests and procedures might be considered obvious, it might also be argued that the Quality and Outcomes Framework in primary care in the UK promotes payment-led inequity between disease-specific patient groups in general practice. And while little may be known about standards or views relating to confidentiality in complementary medicine, there is clear evidence that concerns exist among patients, clinicians, and practice staff about both accidental and systematic breaches of confidentiality in conventional medicine..$^{3-5}$

It is right that poor ethical standards in complementary medicine should be highlighted and condemned. However, critics comment from a weakened position if they do not equally acknowledge ethical shortfalls in conventional medicine.

\section{Brian S Buckley,}

Cochrane Fellow \& Researcher in Primary Care, National University of Ireland, General Practice, 1 Distillery Road, Galway, Ireland. E-mail: bsbuckley@iol.ie

\section{Provenance}

Commissioned; not peer reviewed

\section{REFERENCES}

1. Ernst E. Ethics of complementary medicine: practical issues. Br J Gen Pract 2009; 59: 517-519. Advance online publication. DOI: 10.3399/bjgp09X453404.

2. Barry MJ. Prostate specific antigen testing for early diagnosis of prostate cancer. N Engl J Med 2001; 344(18): 1373-1377.

3. Carlisle J, Shickle G, Cork M, McDonagh A. Concerns over confidentiality may deter adolescents from consulting their doctors. A qualitative exploration. J Med Ethics 2006; 32: 133-137.

4. Robling MR, Hood K, Houston H, Pill R, et al. Public attitudes towards the use of primary care patient record data in medical research without consent: a qualitative study. J Med Ethics 2004; 30: 104-109.

5. Stone MA, Redsell SA, Ling JT, Hay AD. Sharing patient data: competing demands of privacy, trust and research in primary care. Br J Gen Pract 2005 ; 55: 783-789.

DOI: 10.3399/bjgp09X453558

London: General Chiropractic Council, 2005. http://www.gccuk.org/files/link_file/COPSOP_Dec05_WEB(with_glossary)07Jan09.pdf (accessed 21 Apr 2009).

9. Ernst E. What's in a word? Br J Gen Pract 2003; 53(488): 243-244.

10. Ernst E. The ethics of chiropractic. N Z Med J 2008; 121(1281): 96-97.

11. Gilbey A. Use of inappropriate titles by New Zealand practitioners of acupuncture, chiropractic, and osteopathy. NZ Med J 2008; 121(1278): 15-20.

12. Robb S. Use of title 'Dr' - view of the Medical Council of New Zealand. $N$ Z Med J 2008; 121(1279): 112-123.

13. BBC News. Three-month ban for homeopathy GP. 16 January 2003. http://news.bbc.co.uk/1/hi/england/2666411.stm. (accessed 21 Apr 2009).

14. Langworthy JM, le Fleming C. Consent or submission? The practice of consent within UK chiropractic. J Manipulative Physiol Ther 2005; 28(1): $15-24$.

15. Ernst E. Chiropractic: a critical evaluation. J Pain Symptom Manage 2008; 35(5): 544-562.
16. Caspi O, Holexa J. Lack of standards in informed consent in complementary medicine. Complement Ther Med 2005; 13(2): 123-130.

17. Miller FG, Kaptchuk TJ. Acupuncture trials and informed consent. J Med Ethics 2007; 33(1): 43-44.18.

18. Li M, Chen K, Mo Z. Use of qigong therapy in the detoxification of heroin addicts. Altern Ther Health Med 2002; 8(1): 50-54,56-59.

19. Lim B, Schmidt K, White A, Ernst E. Reporting of ethical standards: differences between complementary and orthodox medicine journals. Wien Klin Wochenschr 2004; 116(14): 500-503.

20. James A, Horton R. The Lancet's policy on conflicts of interest. Lancet 2003; 361: 8-9.

21. General Medical Council. Confidentiality: protecting and providing information. London: GMC, 2000.

22. Jones $\mathrm{C}$. The utilitarian argument for medical confidentiality: a pilot study of patients' views. J Med Ethics 2003; 29(6): 348-352.

23. Pizzorno JE, Murray MT. Textbook of natural medicine. Harcourt: Edinburgh. 2001. 